\title{
Pigtail Catheter Use for Draining Pleural Effusions of Various Etiologies
}

\author{
Adel Salah Bediwy ${ }^{1}$ and Hesham Galal Amer ${ }^{2}$ \\ ${ }^{1}$ Chest Department, Faculty of Medicine, Tanta University, Tanta 33633, Egypt \\ ${ }^{2}$ Internal Medicine Department, Faculty of Medicine, Menoufia University, Menoufia, Egypt
}

Correspondence should be addressed to Adel Salah Bediwy, adelsalah1@yahoo.com

Received 12 October 2011; Accepted 31 October 2011

Academic Editor: L. Molinos

Copyright ( 2012 A. S. Bediwy and H. G. Amer. This is an open access article distributed under the Creative Commons Attribution License, which permits unrestricted use, distribution, and reproduction in any medium, provided the original work is properly cited.

\begin{abstract}
Background. Use of small-bore pigtail catheter is a less invasive way for draining pleural effusions than chest tube thoracostomy. Methods. Prospectively, we evaluated efficacy and safety of pigtail catheter (8.5-14 French) insertion in 51 cases of pleural effusion of various etiologies. Malignant effusion cases had pleurodesis done through the catheter. Results. Duration of drainage of pleural fluid was 3-14 days. Complications included pain (23 patients), pneumothorax (10 patients), catheter blockage (two patients), and infection (one patient). Overall success rate was $82.35 \%$ ( $85.71 \%$ for transudative, $83.33 \%$ for tuberculous, $81.81 \%$ for malignant, and $80 \%$ for parapneumonic effusion). Nine cases had procedure failure, five due to loculated effusions, and four due to rapid reaccumulation of fluid after catheter removal. Only two empyema cases (out of six) had a successful procedure. Conclusion. Pigtail catheter insertion is an effective and safe method of draining pleural fluid. We encourage its use for all cases of pleural effusion requiring chest drain except for empyema and other loculated effusions that yielded low success rate.
\end{abstract}

\section{Introduction}

Pleura is divided into a parietal layer which lines the inner aspect of the chest wall and a visceral layer which covers the lung and lines the interlobar fissures [1]. Pleural effusion is the abnormal accumulation of fluid in the pleural space. A pleural effusion is always abnormal and indicates the presence of an underlying disease. Approximately 1.4 million people in the United States develop a pleural effusion each year [2]. Normal liquid and protein enter pleura space from the systemic circulation and are removed by the parietal pleural lymphatics. Because the mesothelial boundaries are leaky, excess liquid can move across into the lower pressure (intrapleural), high-capacitance space and collect as a pleural effusion. These effusions can form based on disease of the pleural membranes themselves or disease of thoracic or abdominal organs [3].

Fluid collection within the pleural cavity can be assessed with clinical and radiological means. When pleural effusion is detected, the characteristics of the fluid (exudate or transudate) must be revealed using thoracocentesis [1].
Tube thoracostomy remains the standard of care for the treatment of pneumothorax and simple effusions in most hospitals [4]. Placement of a large-bore chest tube is an invasive procedure with potential morbidity and complications and therefore the use of small-bore pigtail catheter may be desirable [5].

The aim of this study was to evaluate the efficacy and complications of using pigtail catheter in drainage of pleural effusion as a less invasive alternative to traditional chest tube insertion.

\section{Materials and Methods}

The current work is a prospective noncontrolled study for revision of inpatient pigtail catheter insertions performed between January 2009 and May 2010 at the international hospital of Bahrain, a tertiary care hospital, Kingdom of Bahrain.

All adult patients with pleural effusions who were planned to have chest tube insertion were included. Informed signed consent was obtained from all patients eligible 


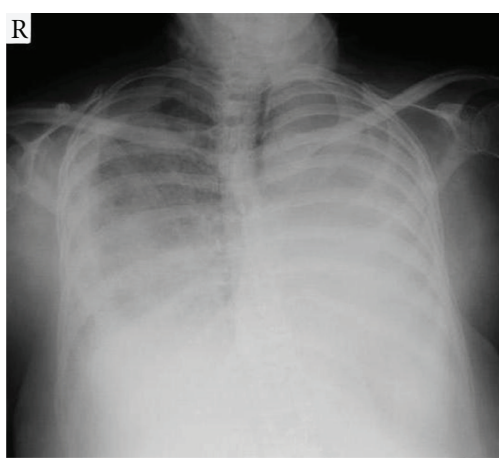

(a)

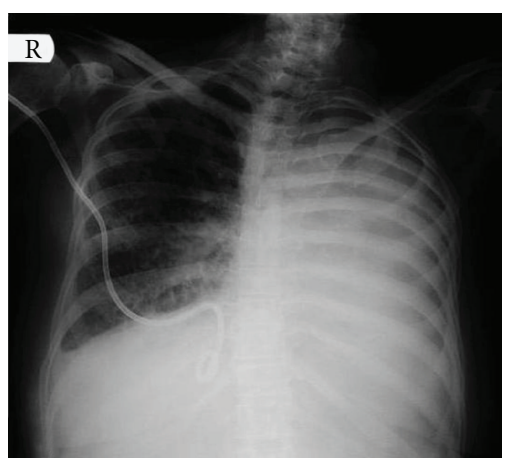

(b)

Figure 1: Right malignant pleural effusion (a) secondary to left bronchogenic carcinoma (with previous left pleurodesis followed by progressive left lung involvement). $\mathrm{X}$ ray done after right pigtail catheter insertion. (b) showed catheter in place with good drainage of effusion.

to participate in the study. The local ethical committee approved the study protocol. The diagnosis of pleural effusion was based on clinical and chest X-ray findings and confirmed by a diagnostic thoracocentesis (less than $50 \mathrm{~mL}$ ).

Pigtail catheters (Dawson-Mueller Drainage Catheters, Cook Medical Interventional Radiology, UK) had the size of 8.5-14 French (2.8-4.7 $\mathrm{mm}$ in diameter).

Detailed history taking and complete medical examination were done to all patients. Coagulation profile was done to all patients. Chest radiographs were done before and after the procedure to determine efficacy of drainage (Figure 1). All procedures were done at the bedside under local anesthesia with 3 to $6 \mathrm{~mL}$ of lidocaine $2 \%$ and with ultrasonic guidance. The site of catheter insertion was determined according to ultrasound findings. In most cases, the site of insertion was in the 5 th or the 6 th intercostals space in the mid-axillary line.

Needles were inserted just above the top of the rib to avoid injury of the intercostal bundle. A small (22 gauge) "finder needle" was employed before inserting the larger needle provided with the kit. Insertion of pigtail catheters was done using the modified Seldinger technique [6] and in accordance with the British Thoracic Society guideline for insertion of chest drain [7]. In brief, few cubic centimeters of pleural fluid were withdrawn with the needle to confirm that the distal end of the needle is inside the pleural cavity, and passage of the guide wire into the pleural space became effortless. Development of an adequate tract with the dilator and insertion of the pigtail catheter so that the side holes are well within the pleural cavity are important for proper function. The pigtail catheters were attached to standard thoracic drainage system (SIMS Portex Limited, Hythe, Kent CT21 6JL, UK). The catheters were removed as soon as the drainage was less than $100 \mathrm{~mL}$ per day for 3 consecutive days.

The therapy was considered successful if the opacity cleared on chest radiograph and confirmed on ultrasonography of the thorax and also if there was no need for a second intervention (repeat pigtail placement, tube thoracostomy, or operation) within 72 hours after removal of the pigtail catheter.

Patients were given, beside pigtail catheter insertion, the standard therapy according to the cause of pleural effusion. For malignant pleural effusion, pleurodesis was done using bleomycin $(0.75 \mathrm{mg} / \mathrm{kg}$ was administered as a single dose. An additional dose was given if daily fluid output did not drop to less than $100 \mathrm{~mL} /$ day within 3 days). For tuberculous pleural effusion, standard antituberculous chemotherapy and corticosteroids were given. For parapneumonic effusions, antibiotics were given according to the American thoracic society recommendations [8]. For cases of heart failure, antifailure treatment and diuretics were given. For hypoproteinemia cases, albumin infusion and diuretics were given.

The end point of the study was either the resolution of the effusion and a decision to remove the catheter or the need for another intervention.

\section{Results}

The current study reviews our experience with 51 cases having pigtail catheters inserted for treatment of pleural effusion over a sixteen-month period. Eleven patients had malignant pleural effusion (five cases secondary to nonsmall cell lung cancer, two cases secondary to breast cancer, two cases secondary to gastrointestinal cancer, and two cases with malignant mesothelioma). Six patients had tuberculous pleural effusion. Twenty patients had parapneumonic effusion: six of them had empyema. Fourteen cases had transudative pleural effusion; eight secondary to heart failure and six secondary to hypoproteinemia. Age and sex of the patients are shown in Table 1.

The duration of drainage of pleural fluid using pigtail catheter ranged between three and 14 days with a mean of $5.8 \pm 2.4$ days. The amount of pleural fluid drained was $2389.4 \pm 480.5 \mathrm{~mL}$ (Table 1 ).

Complications of pigtail catheter included pain at the insertion site requiring analgesia in 23 patients, pneumothorax in ten patients, blockage of the catheter in two patients, and infection in one patient (Table 1). Pneumothoraces were resolved spontaneously through the same catheter. Blockage of the catheters and infection were associated with procedure failure. 
TABle 1: Some demographic, clinical data, and complications of patients having pigtail catheter insertion for pleural effusion.

\begin{tabular}{lc}
\hline Total number & 51 patients \\
Age & $57.27 \pm 13.45$ years \\
Sex & \\
$\quad$ Male & 29 patients $(56.86 \%)$ \\
$\quad$ Female & 22 patients $(43.14 \%)$ \\
Duration of drainage & $5.8 \pm 2.4$ days \\
Amount of drained fluid & $2389.4 \pm 480.5 \mathrm{~mL}$ \\
Complications & \\
$\quad$ Pain at insertion site & 23 patients $(45.09 \%)$ \\
$\quad$ Pneumothorax & 10 patients $(19.6 \%)$ \\
$\quad$ Blockage of the catheter & 2 patients $(3.92 \%)$ \\
Infection & 1 patient $(1.96 \%)$ \\
\hline
\end{tabular}

Pigtail catheter drainage of pleural effusion was successful in 42 out of 51 patients with a success rate of $82.35 \%$. The success rate was highest with transudative pleural effusion (12 out of 14, 85.71\%), followed by tuberculous effusion (five out of six, $83.33 \%$ ), then malignant pleural effusion (nine out of 11,81.81\%), and finally parapneumonic pleural effusion (16 out of 20, 80\%) (Figure 2). Among the six cases of empyema, the procedure was successful only in two of them (success rate $33.33 \%$ ).

Among the nine cases of failure, five of them were due to loculated effusions (four with empyema and one with tuberculous effusion), and four of them were due to rapid re-accumulation of the fluid after removal of the catheter (one case of heart failure, one case of hypoproteinemia, and two cases of malignant effusion with failure of pleurodesis). In both parapneumonic and tuberculous pleural effusion groups, all failures were associated with presence of loculation (Table 2). If the cases of loculated pleural effusions are excluded, the success rate increases to $91.3 \%$ (42 out of 46 ).

\section{Discussion}

The recent interest in the use of small-bore catheters for pleural effusion drainage is based on the idea that it may be less invasive procedure and thus better tolerated by patients compared to standard large-bore chest tubes, with no compromise in efficacy.

In our study, the mean duration of pleural fluid drainage using pigtail catheter was 5.8 days (3-14 days). In other studies, the durations of drainage of pleural fluid using a pigtail catheter were more or less similar to our results. Parulekar et al. [9] reported a mean period of drainage of six days (three to 21 days). Liu et al. [10] reported a mean duration of drainage of 6.1 days. Gammie et al. [11] found a mean duration of drainage of 97 hours. Saffran et al. [12] reported duration of drainage ranged from one to ten days. Patz et al. [13] reported a duration of catheter drainage of two to 11 days (mean 5.1 days).

In the present study, complications of pigtail catheter insertion included pain at the insertion site requiring analgesia $(45.09 \%)$, pneumothorax (19.6\%), blockage of the

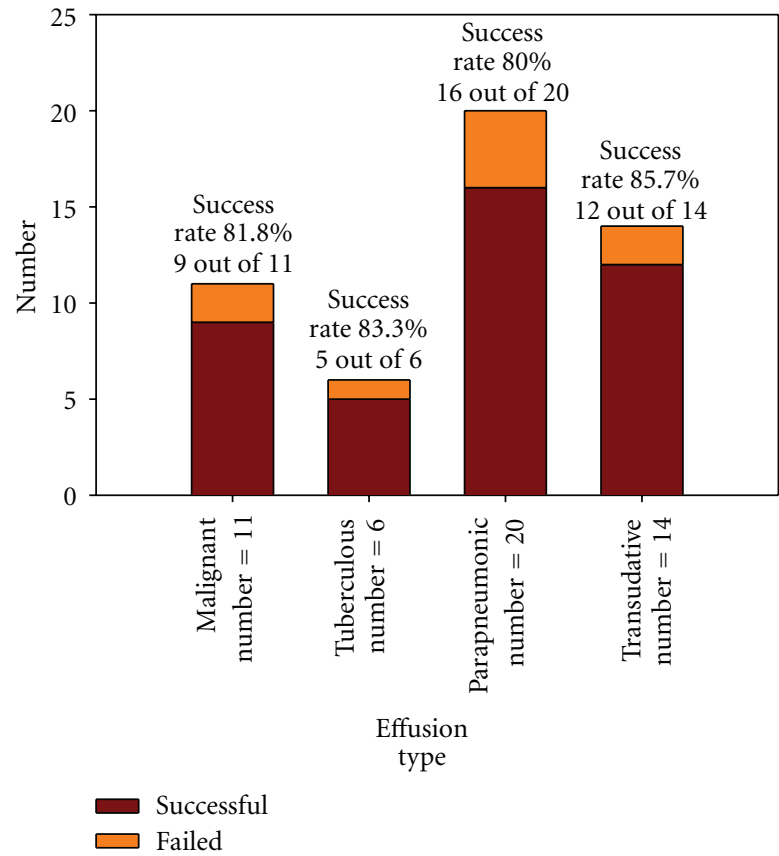

FIGURE 2: Success rate of pigtail catheter insertion in cases of pleural effusion of various etiologies.

catheter $(3.92 \%)$, and infection (1.96\%). Pneumothoraces were resolved spontaneously through the same catheter. Blockage of the catheters and infection were associated with procedure failure.

Pain caused by chest drain insertion is less with using pigtail catheters as they do not impinge on the neurovascular bundle or alter the geometry of the intercostals space. In contrast, chest tubes, with their excessive size, cause pain by compressing the neurovascular bundle at the top of the intercostals space as well as by levering open the intercostals space [14].

On reviewing the literatures, pigtail catheter insertion was usually safe with little chance for complications. Roberts et al. [5] found that five percent of pigtail catheter placements were associated with serious complications (hemothorax, pnuemothorax, and hepatic perforation) and the overall complications of catheter use occurred in $20 \%$ of patients and included failure to drain, dislodgement, kinking, empyema, and disconnection.

Walsh et al. [15] found minimal complications with the use of pigtail catheter for pleural effusion drainage. Spontaneously resolving, small, apical pneumothoraces developed in four of the 15 patients. One patient experienced reexpansion pulmonary edema.

Seaton et al. [16] found that the complication rate was low and consisted of symptoms such as pain and fever with using small tube drainage and doxycycline sclerotherapy.

Liu et al. [10] reviewed 276 patients who underwent pigtail catheters (size from ten to 16 French) under ultrasound guidance for drainage of pleural effusions of various etiologies and pneumothoraces. Only ten (3.0\%) drains had complications due to the procedure, including 
TABLE 2: Clinical details of patients with failed pigtail catheter insertion.

Case no. Clinical details

60-year-old female with malignant pleural effusion. Pigtail catheter was removed after pleurodesis. Fluid reaccumulated indicating failure of pleurodesis.

67-year-old male with malignant pleural effusion. Pigtail catheter was removed after pleurodesis. Fluid re-accumulated indicating failure of pleurodesis.

45-year-old male with tuberculous pleural effusion (loculated). Serial radiography showed persistence of the effusion with failure of the drainage.

52-year-old female with empyema with loculations. Pigtail catheter was blocked with failure of the drainage. Trial of clearing the catheter using the guide wire failed.

59-year-old male with empyema with loculations. Serial radiography showed persistence of the effusion with failure of the drainage.

67-year-old male with empyema with loculations. Pigtail catheter was blocked with failure of the drainage. Trial of clearing the catheter using the guide wire failed.

58-year-old male with empyema with loculations. Serial radiography showed persistence of the effusion with failure of the drainage.

67-year-old male with transudative effusion due to hypoproteinemia caused by chronic liver disease. Fluid re-accumulated after removal of the pigtail catheter.

41-year-old female with transudative effusion due to heart failure. Fluid re-accumulated after removal of the pigtail catheter and it was infected.

infection (1.2\%), dislodgment (1.2\%), wound bleeding at the puncture area complicated with hemothoraces $(0.3 \%)$, and lung puncture $(0.3 \%)$. There was no significant difference in success rate when different catheter sizes were used to treat pleural diseases.

The incidence and significance of pneumothorax after small-bore catheter placement for malignant pleural effusions was examined by Chang et al. [17] in a retrospective review of 88 patients treated over a two-year period. Twentyseven patients (31\%) developed a pneumothorax. Resolution occurred in 22 patients. No complications such as tension pneumothorax or respiratory distress were reported. In another study, Morrison et al. [18] found that pneumothorax occurred in $19 \%$ of cases with malignant pleural effusion treated with pigtail catheter insertions. All pneumothoraces were insignificant and authors attribute them to the use of Seldinger technique.

Saffran et al. [12] used a $14 \mathrm{~F}$ pigtail catheter in ten patients with malignant pleural effusion in an ambulatory base and after that pleurodesis was done with talc. Catheter dislodgment occurred in two patients with inability to do pleurodesis. One experienced a hydropneumothorax, for which pleurodesis was unsuccessful. One died in hospital on day 26 after pleurodesis despite radiographic resolution.

Patz et al. [13] published a series of 19 patients with malignant effusions who underwent ambulatory pleurodesis (with bleomycin) using small-bore (10.3F) catheter drainage. One patient had a wound infection and empyema that necessitated hospitalization for six days.

Warren et al. [19] used pigtail catheter in 202 patients with symptomatic malignant pleural effusions on an outpatient basis. Reaccumulation of the pleural effusion occurred in $3.8 \%$ of cases. The incidence of infection was $2.2 \%$. The incidence of blockage was $4.8 \%$.
In the present study, pigtail catheter drainage of pleural effusion was successful in $82.35 \%$ of cases. The success rate was highest with transudative pleural effusion (85.71\%), followed by tuberculous effusion $(83.33 \%)$, then malignant pleural effusion $(81.81 \%)$, and finally parapneumonic pleural effusion (80\%). Among the six cases of empyema, the procedure was successful only in two of them (success rate $33.33 \%)$.

Success rates of using pigtail catheter in other studies were comparable to our findings. Liu et al. [10] found that the success rate of pigtail catheter insertion was highest when the drain was used to treat massive transudate effusions (81.6\%) and malignant pleural effusions (75.5\%), followed by parapneumonic effusions/empyemas $(72.2 \%)$, hemothoraces $(66.6 \%)$, and pneumothoraces $(64.0 \%)$.

In another study, Liang et al. [20] found that the success rate of ultrasound-guided pigtail catheter drainage of pleural effusions in the ICU was highest when used to treat traumatic hemothorax $(100 \%)$ and postoperative pleural effusions $(85 \%)$; drains inserted for empyema were more likely to fail (overall success rate, $42 \%$ ). No significant insertion complications, such as hollow organ perforation, were caused by this procedure.

Gammie et al. [11] found that clinical success rates of pigtail catheter insertion for drainage of pleural effusion were $86 \%$ with no reported complications.

Grodzin and Balk [21] demonstrated that the use of a small indwelling pleural catheter was more cost-effective when used in place of a closed tube thoracostomy for drainage of large-volume pleural effusions.

Chung et al. [22] demonstrated that pigtail catheter insertion may hasten resolution of tuberculous pleural effusion and reduce the occurrence of residual pleural thickening. On the contrary, Lai et al. [23] found that pigtail 
catheter insertion for cases of tuberculous pleural effusion had no beneficial effects on residual pleural thickening development and did not shorten the duration of fever. The only positive effect found in the drainage group was a more rapid resolution of dyspnoea.

In accordance with the results of our study, Sartori et al. [24] reported a success rate of $84.3 \%$ with using a nineFrench intrapleural catheter insertion under sonographic guidance followed by bleomycin pleurodesis in 160 patients with rapidly recurrent malignant pleural effusion.

Seaton et al. [16] studied the use of small tube drainage and doxycycline sclerotherapy for malignant pleural effusion and reported a success rate of $81 \%$.

Parker et al. [25] compared the efficacy of small-bore catheter drainage and pleurodesis to traditional drainage with standard chest tube in 24 malignant pleural effusions. Eight of 13 effusions were adequately treated using the smallbore catheter, compared with four of 11 effusions treated with the standard chest tube.

In a retrospective study, Parulekar et al. [9] found that small-bore catheter 12 French was as effective as standard chest tube for drainage of malignant pleural effusion and pleurodesis without significant differences in the rate of complications.

Walsh et al. [15] treated 15 consecutive patients with symptomatic malignant pleural effusion using a nine-French catheter. Eleven of 12 patients who lived for more than four weeks had objective clinical responses.

Patz et al. in [13] reported a success rate of $79 \%$ with the use of ambulatory pigtail catheter and pleurodesis for malignant effusions.

In our study, it was found that among the nine cases of failure, five of them were due to loculated effusions, and four of them were due to rapid reaccumulation of the fluid after removal of the catheter. In both parapneumonic and tuberculous pleural effusion groups, all failures were associated with presence of loculation. We found that exclusion of patients with preplacement evidence of loculated effusions would have yielded a success rate of $91.3 \%$ for effusions treated by pigtail catheter drainage.

Gammie et al. [11] found that eleven out of 77 pigtail catheter placements for pleural effusions were not successful. Four failures were associated with loculated fluid collections that required either operation or radiographically guided drainage for resolution. In two cases, pigtail catheters were removed when they were draining in excess of $1000 \mathrm{~mL}$ of fluid per day, and the underlying effusions reaccumulated. They reported that exclusion of patients with preplacement evidence of loculated effusions and postponement of pigtail removal in the face of excess drainage would have yielded a success rate of $94 \%$ for effusions treated by pigtail catheter drainage.

\section{Conclusion}

Pigtail catheter insertion is an effective and safe method of draining pleural fluid. We encourage its use for all cases of pleural effusion requiring chest drain except for empyema and other loculated pleural effusions that yielded low success rate. Future studies are needed to compare pigtail catheter and other small bore drains with and without using Seldinger technique.

\section{References}

[1] I. Gotsman, Z. Fridlender, A. Meirovitz, D. Dratva, and M. Muszkat, "The evaluation of pleural effusions in patients with heart failure," American Journal of Medicine, vol. 111, no. 5, pp. 375-378, 2001.

[2] M. L. Mayse, "Non-malignant pleural effusions," in Fishman's Pulmonary Diseases and Disorders, A. P. Fishman, J. A. Elias, J. A. Fishman, M. A. Grippi, R. M. Senior, and A. I. Pack, Eds., pp. 1487-1504, Mcgrow-Hill, New York, NY, USA, 4th edition, 2008.

[3] V. C. Broaddus and R. W. Light, "Pleural effusion," in Murray and Nadel's Textbook of Respiratory Medicine, R. J. Mason, J. F. Murray, V. C. Broaddus, and J. A. Nadel, Eds., pp. 1913-1951, Elsevier, 4th edition, 2005.

[4] E. R. Munnell, “Thoracic drainage," Annals of Thoracic Surgery, vol. 63, no. 5, pp. 1497-1502, 1997.

[5] J. S. Roberts, S. L. Bratton, and T. V. Brogan, "Efficacy and complications of percutaneous pigtail catheters for thoracostomy in pediatric patients," Chest, vol. 114, no. 4, pp. 11161121, 1998.

[6] S. I. Seldinger, "Catheter replacement of the needle in percutaneous arteriography; a new technique," Acta radiologica, vol. 39, no. 5, pp. 368-376, 1953.

[7] D. Laws, E. Neville, and J. Duffy, "BTS guidelines for the insertion of a chest drain,” Thorax, vol. 58, no. 2, pp. ii53-ii59, 2003.

[8] L. A. Mandell, R. G. Wunderink, A. Anzueto et al., "Infectious Diseases Society of America/American Thoracic Society Consensus Guidelines on the management of communityacquired pneumonia in adults," Clinical Infectious Diseases, vol. 44, no. 2, pp. S27-S72, 2007.

[9] W. Parulekar, G. Di Primio, F. Matzinger, C. Dennie, and G. Bociek, "Use of small-bore vs large-bore chest tubes for treatment of malignant pleural effusions," Chest, vol. 120, no. 1, pp. 19-25, 2001.

[10] Y. H. Liu, Y. C. Lin, S. J. Liang et al., "Ultrasound-guided pigtail catheters for drainage of various pleural diseases," American Journal of Emergency Medicine, vol. 28, no. 8, pp. 915-921, 2010.

[11] J. S. Gammie, M. C. Banks, C. R. Fuhrman et al., "The pigtail catheter for pleural drainage: a less invasive alternative to tube thoracostomy," Journal of the Society of Laparoendoscopic Surgeons, vol. 3, no. 1, pp. 57-61, 1999.

[12] L. Saffran, D. E. Ost, A. M. Fein, and M. J. Schiff, "Outpatient pleurodesis of malignant pleural effusions using a small-bore pigtail catheter," Chest, vol. 118, no. 2, pp. 417-421, 2000.

[13] E. F. Patz, H. P. McAdams, P. C. Goodman, S. Blackwell, and J. Crawford, "Ambulatory sclerotherapy for malignant pleural effusions," Radiology, vol. 199, no. 1, pp. 133-135, 1996.

[14] J. D. Luketich, M. Kiss, J. Hershey et al., "Chest tube insertion: a prospective evaluation of pain management," Clinical Journal of Pain, vol. 14, no. 2, pp. 152-154, 1998.

[15] F. W. Walsh, W. M. Alberts, D. A. Solomon, and A. L. Goldman, "Malignant pleural effusions: pleurodesis using a small-bore percutaneous catheter," Southern Medical Journal, vol. 82, no. 8, pp. 963-972, 1989. 
[16] K. G. Seaton, E. F. Patz, and P. C. Goodman, "Palliative treatment of malignant pleural effusions: value of smallbore catheter thoracostomy and doxycycline sclerotherapy," American Journal of Roentgenology, vol. 164, no. 3, pp. 589591, 1995.

[17] Y. C. Chang, E. F. Patz, and P. C. Goodman, "Pneumothorax after small-bore catheter placement for malignant pleural effusions," American Journal of Roentgenology, vol. 166, no. 5, pp. 1049-1051, 1996.

[18] M. C. Morrison, P. R. Mueller, M. J. Lee et al., "Sclerotherapy of malignant pleural effusion through sonographically placed small-bore catheters," American Journal of Roentgenology, vol. 158, no. 1, pp. 41-43, 1992.

[19] W. H. Warren, R. Kalimi, L. M. Khodadadian, and A. W. Kim, "Management of malignant pleural effusions using the pleurx catheter," Annals of Thoracic Surgery, vol. 85, no. 3, pp. 10491055, 2008.

[20] S. J. Liang, C. Y. Tu, H. J. Chen et al., "Application of ultrasound-guided pigtail catheter for drainage of pleural effusions in the ICU," Intensive Care Medicine, vol. 35, no. 2, pp. 350-354, 2009.

[21] C. J. Grodzin and R. A. Balk, "Indwelling small pleural catheter needle thoracentesis in the management of large pleural effusions," Chest, vol. 111, no. 4, pp. 133-135, 1997.

[22] C. L. Chung, C. H. Chen, C. Y. Yeh, J. R. Sheu, and S. C. Chang, "Early effective drainage in the treatment of loculated tuberculous pleurisy," European Respiratory Journal, vol. 31, no. 6, pp. 1261-1267, 2008.

[23] Y. F. Lai, T. Y. Chao, Y. H. Wang, and A. S. Lin, "Pigtail drainage in the treatment of tuberculous pleural effusions: a randomised study," Thorax, vol. 58, no. 2, pp. 149-151, 2003.

[24] S. Sartori, D. Tassmari, P. Ceccotti et al., "Prospective randomized trial of intrapleural bleomycin versus interferon alfa- $2 b$ via ultrasound-guided small-bore chest tube in the palliative treatment of malignant pleural effusions," Journal of Clinical Oncology, vol. 22, no. 7, pp. 1228-1233, 2004.

[25] L. A. Parker, G. C. Charnock, and D. J. Delany, "Small bore catheter drainage and sclerotherapy for malignant pleural effusions," Cancer, vol. 64, no. 6, pp. 1218-1221, 1989. 


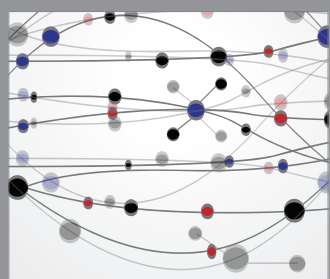

The Scientific World Journal
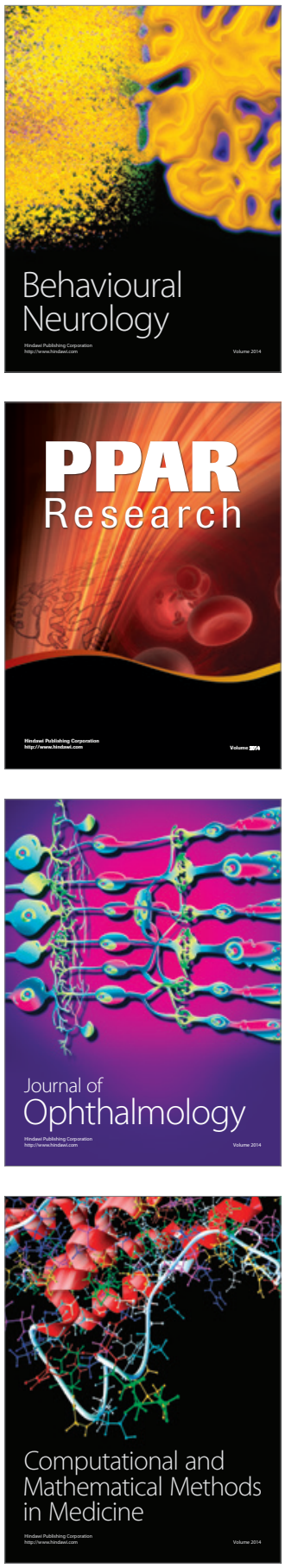

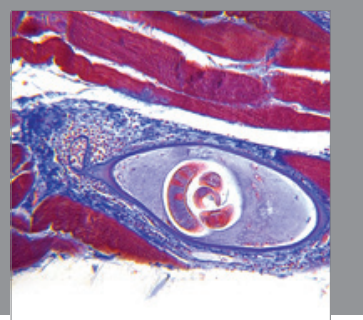

Gastroenterology

Research and Practice
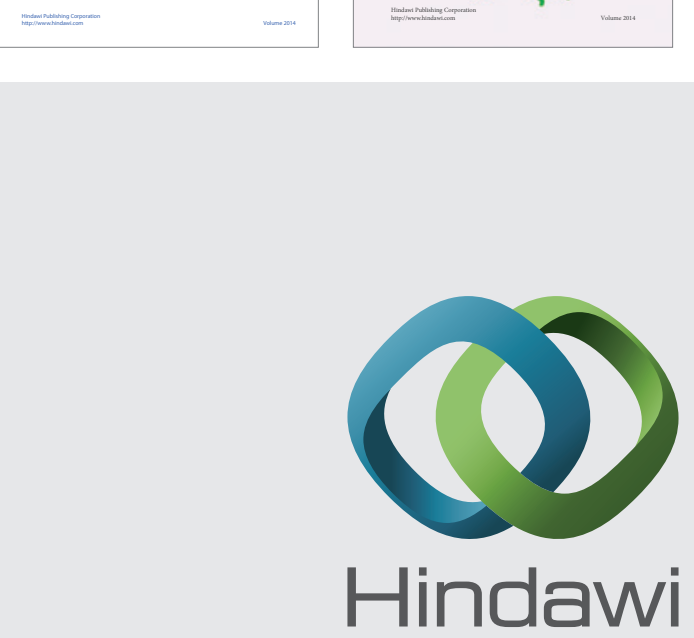

Submit your manuscripts at

http://www.hindawi.com
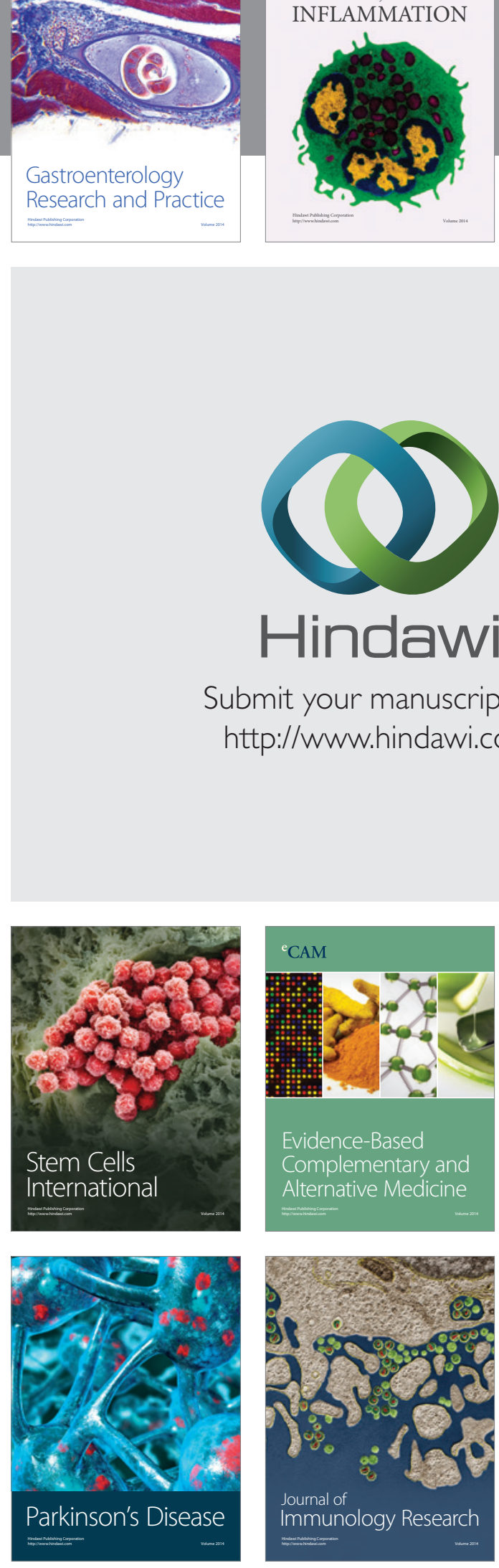

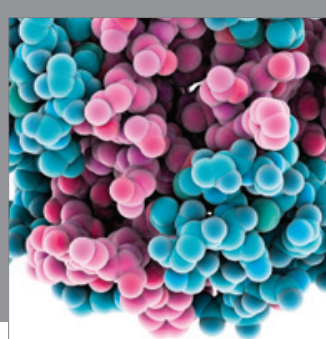

Diabetes Research
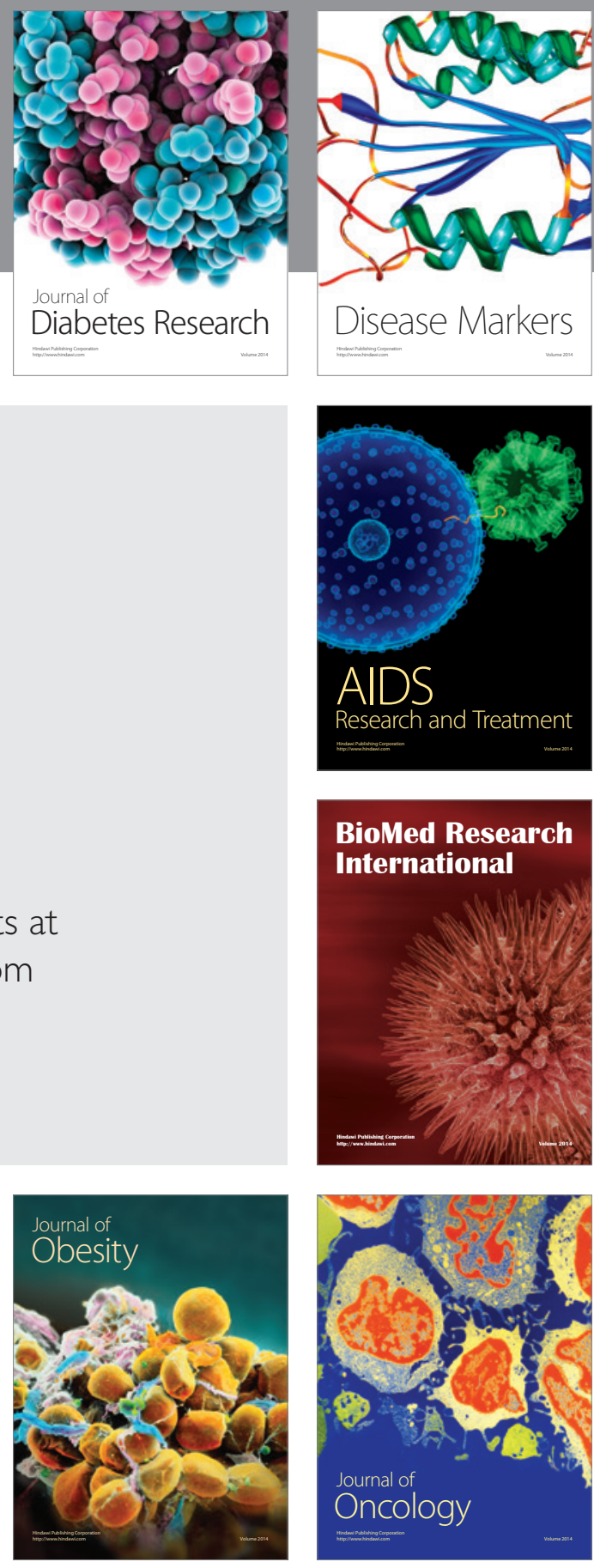

Disease Markers

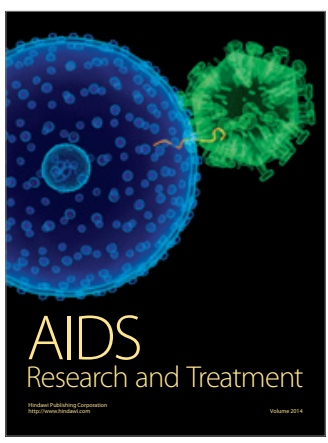

BioMed Research

International
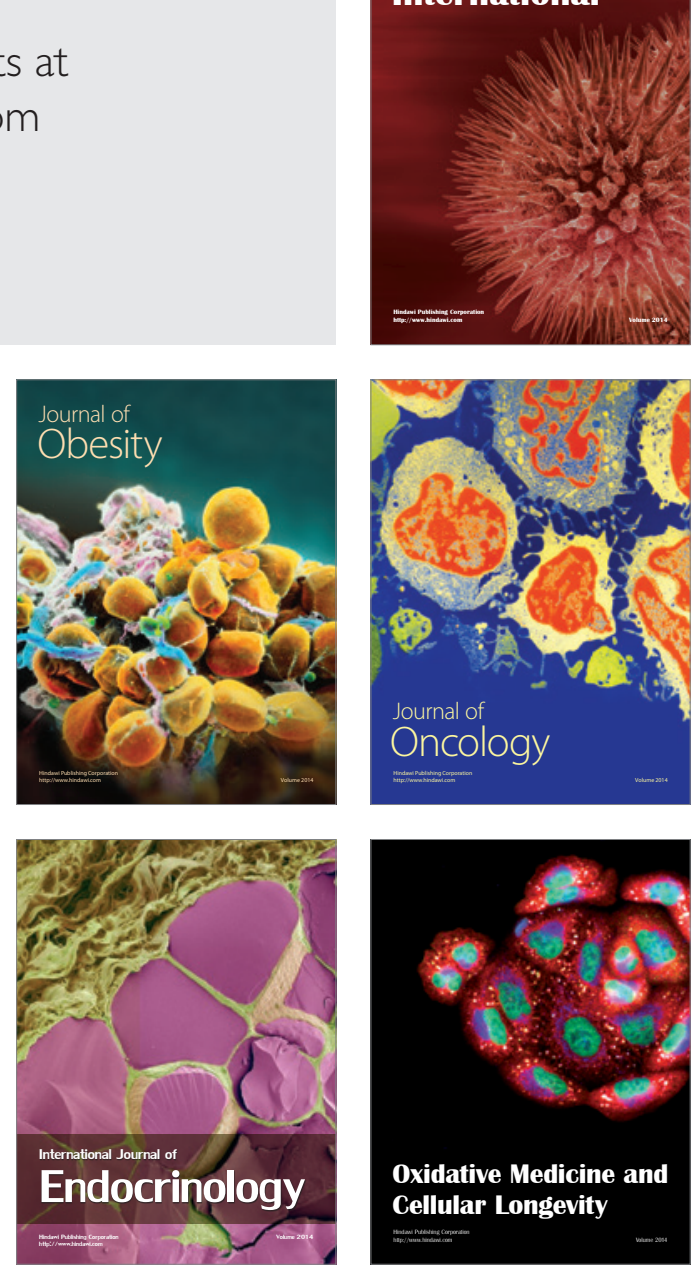